tractor, although differing from the latter form to a certain extent. With the discharge orifice of this form a fair speed was obtained, whereas with ordinary discharges the boat could hardly be moved along.

The Kev. Mr. Capell, the originator of this discharge nozzle, gave particulars of the experiment made with the vessel, and concluded that the success of jet propulsion depended on the form of the discharge nozzle. The particulars given were not sufficiently detailed to enable the problem to be adequately discussed, and it would be requisite to know, before arriving at any conclusion, whether the observations taken were properly verified, and the recording instruments were sufficiently trust worthy for implicit reliance to be placed upon them.

Mr. Walker's paper was on an interesting subject, and some of the experiments which he showed were of a practical nature. They will be doubtless useful to those not acquainted with the details of this field of research. The question of relation of speed, power absorbed, and air discharged with propeller ventilating fans was discussed. Seventeen three-bladed fans were tried, being driven by a continuous-current serieswound electrical motor of about one-third electrical horsepower. The current was taken off the mains of the Westminster Electric Supply Corporation. The fans were run at a speed up to six hundred revolutions a minute; the velocity of the air was measured by an anemometer. The results, which are too voluminous to quote in full, were contained in tables attached to the paper. The effect of cross section of fan-blades was discussed in the paper. The blades were of sheet-iron; all, excepting one, of $1 / 16$ inch thick. Their cross sectional lines were all composed of straight lines or arcs of circles. The fans in each group differed from one another only in the cross section of their blades, which were flat, plano-convex, or concavo: convex of different degrees of curvature. A notable feature of the experiments made by the author was that the effect of putting a curved surface upon the back of a flat-bladed fan, thus giving a plano-convex section, was to increase the mechanical efficiency 28 per cent., the volumetric efficiency 54 per cent., and the pressure efficiency $\mathrm{I} \cdot 4$ per cent. The angle of the blades was $17^{\circ}$. The most efficient fan of the group was one having a blade concavo-convex in section with a hollow space between the faces, when the mechanical, volumetric, and pressure efficiencies were respectively 28,65 , and 2 I per cent. The efficiencies were thus increased by making the blades thicker in the middle of their breadth. To test the effect of feeding the fans from the tips of the blades the delivery tube through which the air was passed was moved forward, the fan thus being outside the tube. This increased the mechanical, volumetric and pressure efficiencies from $16^{\circ}, 62^{\circ} \mathrm{O}$, and $2^{\circ} \mathrm{O}$ to $29^{\circ} 4,78^{\circ} \mathrm{O}$, and $3^{\text {.I }}$ per cent. respectively. The velocity of air on entering and leaving the fans was measured by the anemometer. Experiments were made to test the effect of a contracted outlet and inlet. The fan worked partly in a delivery tube, the outer end of which was partially closed by plates with holes of varying sizes. The efficiency was naturally much reduced. It was anticipated that the slow speed of the blades near the centre partly accounted for this, and a circular disc was therefore fixed in front of the fan on the delivery side. This prevented the air passing back again through the centre of the fan, which it might do owing to the slow speed, and the efficiency was raised. The more the delivery orifice was closed, the larger had to be the disc.

Without entering into theoretical views as to the action of the blades, the author stated that, having regard to the stream-line principle, the section of the blades should be as ship-shape as possible. The two losses in an air-propeller are rotary motion imparted to the air, and skin friction of the blades. The loss from the latter cause was found to be comparatively small by means of experimenting with flat thin blades set at a plane coinciding with the plane of rotation.

The summer meeting of this Institution will be held this year in Birmingham, during the last week in July.

\section{ANNUAL MEETING OF THE U.S. NATIONAL} ACADEMY OF SCIENCES.

THE National Academy of Sciences held its annual meeting at Washington, April 20-22, with about the usual attendance of members, but a marked paucity of papers, only fourteen having been read, of which number five were biographies.
These were of Dr. G. Brown Goode, by Prof. S. P. Langley; of Prof. Thomas L. Casey, by Prof. H. L. Abbot; of Prof. Charles E. Brown-Séquard, by Prof. H. P. Bowditch (by title); of Prof. Huhert A. Newton, by Prof. J. W. Gibbs; and of Mr. George IH. Cook, by Prof. G. K. Gilbert.

An experimental study on the influence of environment upon the biological processes of the various members of the colongroup of bacilli, by Dr. Adelaide Ward Peckham, was presented by Prof. J. S. Billings.

Prof. T. C. Mendenhall read a paper on the energy involved in recent earthquakes. He also read a paper on a ring pendulum for absolute determinations of gravity, giving results of a sug. gestion of Mr. A. S. Kimball that a disc of metal vibrating in its own plane would constitute an improved apparatus for such determinations. This gives the equivalent of a pendulum of any length from infinity to that of the diameter of the outer circumference of the ring. The ring is suspended from its inner circumference; and the length of the equivalent pendulum is computed by the following formula, in which $l$ is the length required, $R$ is radius of the outer, and $R_{2}$ is that of the inner circle :-

$$
l=\frac{\mathrm{R}^{3}+3^{\mathrm{R}^{2}}}{\mathrm{R}_{2}}
$$

With a crudely prepared disc of this description, results were obtained correct to one part in 10,000.

Prof. S. C. Chandler read a paper on variation of latitude, a full abstract of which will appear in NATURE. He also presented another paper on variation of latitude and constant of aberration from observations at Columbia University, by Messrs. J. K. Rees, H. Jacoby, and H. S. Davis. These observers report a series of observations extending from May 9, I893, till June I4, I894, divided into groups of from 30 to 100. They confirm Chandler's period of about 427 days. 'They also fix accurately the latitude of the observatory of Columbia University, which is $40^{\circ} 48^{\prime} 27^{\prime \prime} \cdot 195$

Prof. A. A. Michelson gave a description of a new harmonic analyser, an apparatus devised by him, which enables him to integrate in a few minutes long and difficult problems such as would require weeks for mathematical solution.

In his paper on the position of the Tarsiids and relationship to the phylogeny of man, Prof. Theodore Gill maintained that man is more nearly allied to the chimpanzee and the gorilla than to the orang-outang; the abbreviation of arms and loss of cranial ridges having been caused by disuse of arms for tree climbing, and of teeth for crushing branches, \&c., so that powerful facial muscles were no longer required, nor the ridges to which they were attached. The teeth also approached more closely together, filling up the gaps in jaw of apes. Children still show ancestral type in disproportionate length of arm.

Prof. A. Agassiz read a paper on some recent borings in coral reefs, in which he maintains that the old Darwinian theory of subsidence is no longer tenable, as that would require a thickness of 2000 feet in such reers, but in most cases examined the thickness was within I 30 feet. Observations include the Yucatan atoll, about 30 fathoms; Solomon Islands, I25 to 130 feet ; Florida elevated reef, 60 feet, but this has been denuded and may have been originally of twice this thickness; along the coast of Cuba, 145 feet. Prof. Agassiz attempted to measure the thickness of the great coral reef near Australia, which is 1500 miles long, and 50 to 75 miles wide; but could not yet obtain accurate results. He is confident, however, that the thickness of it is only 25 to 30 fathoms. Prof. Agassiz concludes, however, that barrier, fringing and atoll reefs are none of them thick.

Prof. A. W. Wright read a paper on some recent experiments in Röntgen rays. By using plane glass he obviates the misleading action of a prism in which the thick part absorbs rays, and indicates an apparent negative index of refraction. No indication of refraction was found, however, in using plane glass arranged at an angle so that it would refract rays of light. A thin beam of $\mathrm{X}$-rays was also passed between the poles of a powerful magnet. The poles were then reversed, but no change in the direction of the rays could be detected. Some very recent experiments, however, which he has not yet fully verified, seem to show that perhaps these rays may be diffracted, even if not capable of being refracted. The conjecture is due to the fact that, on passing the beam through a platinum net-work in the manner described, faint interference lines seemed to be produced.

NO. 1436 , VOL. 56 ] 
Prof. Asaph Hall was elected vice-president; Prof. Ira Remsen, home secretary; and Prof. A. Graham Bell, treasurer. New members elected were Messrs. Wm. H. Dall (of Washington); Frank A. Gooch (of Yale); Chas. S. Minot (of Boston); and E. W. Morley (of Cleveland).

The autumn meeting of the Academy will be held at Boston on November 16 next.

\section{CONTINUATION OF EXPERIVENTS ON ELECTRIC PROPERTIES OF URANIUM. ${ }^{1}$}

I $N$ a paper read before the Society on March $\mathbf{I}$, we had the honour to communicate some preliminary results on the electric properties of uranium. We propose now to give other results on the same subject, bearing on the conductance induced in air by uranium.

To measure the leakage in air at ordinary pressure at different voltages, we used in our first experiments the two-Leydens method described in a former paper. We found that the leakage was not proportional to the electro-motive force. It was not perceptibly increased when the uranium was heated, or when the sunlight fell on it.

We also observed the leakage in hydrogen, oxygen, and carbonic acid. The experimental arrangements necessary for this are described in a paper published by the Royal Society of Edinburgh. We found that the rate of leakage is greater in oxygen than in air. The ratio of the rates depends on the voltage chosen. The leakage in hydrogen is less than in air. In carbonic acid it is less for four volts per two $\mathrm{cms}$., but greater for ninety volts per two cms. than it is in air ; for the latter voltage the leakage in carbonic acid is greater even than the corresponding leakage for oxygen at ordinary pressure. We also made experiments with air, hydrogen, oxygen, and carbonic acid at different atmospheric pressures. We found that the leakage in air at pressures ranging from $760 \mathrm{mms}$. to $23 \mathrm{mms}$. was very nearly proportional to the atmospheric pressure. The rate of leakage for lower pressures was so slow as to make the results not very trustworthy. At pressures under $2 \mathrm{cms}$. no appreciable leakage with 4 or with 90 volts per two cms. was observed. With hydrogen, oxygen, and carbonic acid the rate of leakage at higher pressures was somewhat approximately proportional to the pressure, at lower ones to the square root of the pressure.

We found that at ordinary atmospheric pressure, sparking took place in air at 4800 volts, between a rough fragment of uranium and a metal tube around it, connected to the two electrodes of a vacuum-tube within which they were fixed. At 232 mms. pressure, the potential necessary to produce a spark fell to between 1500 and 2000 volts. At $127 \mathrm{mms}$. it had fallen to between IIOO and I 300 volts. At $54 \mathrm{mms}$. it was 700 volts; at $7 \mathrm{mms} .420$ volts; at $2 \mathrm{mms}$. about 400 volts. At $\mathrm{r} / 1000 \mathrm{~mm}$. the voltage necessary to produce sparking rose again to 2000 volts.

To measure the potential difference between two mutually insulated metals when the air between them is rendered conductive by the presence of uranium, we used two methods, which are described more particularly in the paper above referred to. The steady reading obtained when the quadrants of an electrometer were in metallic connection we shall call the metalliczero. The deviation from the metallic-zero, when the quadrants were insulated, to a steady point-the uranium-conductance-zero, as we shall call it-m-depended on the volta difference between the two opposed surfaces of metals, more or less tarnished as they generally were. This deviation took place gradually in about half a minute with one arrangement of apparatus, and in about four minutes with a second arrangement. On the other hand, if the insulated metal had a charge given to it of such an amount as to cause the electrometer reading to deviate from the metallic zero beyond the uranium-conductance-zero, the reading quickly fell to this conductance-zero, and there remained steady.

The following table gives the potential differences between the electrometer wires, when one of them is connected with uranium, and the other with a plate of one or other of the named metals opposed to it :-

1 By Lord Kelvin, Dr. J. Carruthers Beattie, and Dr. M. S. de Smolan. Read before the Royal Society of Edinburgh, April 4.
Metal.

Polished aluminium (I) immediately after being polished

Polished aluminium $\left(\begin{array}{lllll}\cdots & \cdots & \cdots & \ldots & \ldots\end{array}\right.$

$\begin{array}{llllll} & & & & \\ & \ldots & \ldots & \ldots & \ldots & -\mathrm{I}\end{array}$

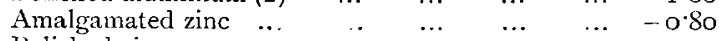

$\begin{array}{lllllll}\text { Polished zinc } \ldots & \ldots & \ldots & \ldots & \ldots & \ldots & -0 \\ \text { Unpolish }\end{array}$

$\begin{array}{llllllll}\text { Unpolished zinc } & \ldots & \ldots & \ldots & \ldots & \ldots & -0.55\end{array}$

$\begin{array}{lllllll}\text { Polished lead... } & \ldots & \ldots & \ldots & \ldots & \ldots & -0.55\end{array}$

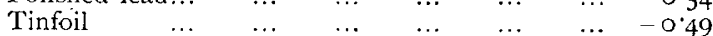

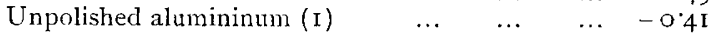

$\begin{array}{llllll}\text { Polished copper } \quad \ldots & \ldots & \ldots & \ldots & \ldots & -0.17\end{array}$

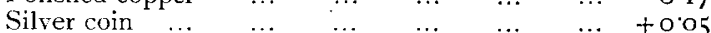

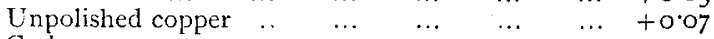

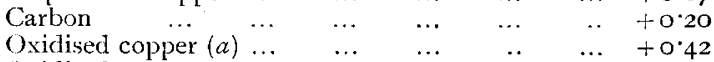

Oxidised copper $(b) \ldots \quad \ldots \quad \ldots \quad \ldots \quad \ldots \quad \ldots \quad \ldots+0.90$

It will be noticed that the difference of potential observed depends very much on the state of polish of the metal concerned. With a third specimen of oxidised copper a potential difference of +0.35 of a volt was obtained. This specimen was afterwards connected to sheaths; a piece of polished aluminium was placed opposite it, and connected to the insulated terminal of the electrometer. The uranium disc, insulated on paraffin, was then placed between them, and the deviation observed was equivalent to a potential difference of $-1 \cdot 53$ volts that is, we obtained an effect equivalent to the sum of the effects we had when the metals were separately insulated in air opposite to uranium.

We observed also the effect of various screens on the rate of reaching the conductance-zero. For example, when a sheet of lead about $2 \mathrm{mms}$. in thickness was used as screen, no deviation from the metallic-zero was obtained. In other words, lead $2 \mathrm{mms}$. thick is not transparent to the uranium influence. Glass $3 \mathrm{mms}$. thick did not entirely stop the deviation; it reduced the deviation in the first minute, however, to $\frac{1}{6}$ of the amount obtained with no screen. A copper screen, $0^{\circ} 24 \mathrm{~mm}$. in thickness, reduced the rate to $\frac{1}{3}$; two copper screens, total thickness $0.48 \mathrm{~mm}$., reduced it to $\frac{1}{12}$; three copper screens, $0.72 \mathrm{~mm}$. reduced it to $\frac{1}{1}$. A mica screen did not reduce the rate at all. $A$ zinc screen, $0.235 \mathrm{~mm}$. thick, reduced it to $\frac{1}{2}$. Two zinc screens, total thickness $0.47 \mathrm{~mm}$, reduced it to $\frac{1}{7}$. Paraffin, $3 \mathrm{mms}$. thick, when placed between the two mutually insulated metals, stopped the deviation from the metallic to the conductance-zero.

The final difference of potential observed between the electrometer wires connected to two mutually insulated metals, when the air between them was made conductive by uranium, was found to be independent of the distance between the metals through distances ranging from less than $\frac{1}{2} \mathrm{~cm}$. to $8 \mathrm{cms}$.

The difference of potential observed when two mutually insulated metals were brought into electric connection with one another by a drop of water, was in the same direction as the uranium conductance-zero between the two surfaces when dry, and was smaller in magnitude. On the other hand, when the uranium surface was covered with water to the depth of about a millimetre, and an air space left above the water, between the submerged uranium surface and the opposed insulated metal, so that we had uranium-water-air-metal, the rate of deviation from the metallic-zero was reduced so much as to be scarcely observable.

We found that the uranium-conductance-zero between zinc and uranium was the same in air, hydrogen, and oxygen. And that the final steady reading did not depend on the atmospheric pressure, though the rate at which this steady reading was reached did largely depend on the atmospheric pressure.

\section{UNIVEKSITY AND EDUCATIONAL INTELLIGENCE.}

CAMBRIDGE. - Dr. Nansen has made a contribution of $£ 5^{\circ}$ towards the teaching of Geography in the University.

The voting of the Senate on the resolutions respecting degrees for women will take place from I to $3 \mathrm{p} . \mathrm{m}$. on Friday, May $2 \mathrm{I}$, in the Senate House.

The University of Madras is to be added to the list of Indian Universities which are affiliated to the University of Cambridge. 